\title{
Intraspecific killing among leopards (Panthera pardus) in Iran (Mammalia: Felidae)
}

\author{
Mohammad S. Farhadinia ${ }^{a, b,{ }^{*}, \text { Hossein Alinezhad }}{ }^{c}$, Ehsan Hadipour ${ }^{c}$, \\ Iman Memarian ${ }^{d}$, Stephane Ostrowski ${ }^{e}$, Kaveh Hobeali $^{b}$, Amirhossein $^{\prime}$ \\ Dadashi-Jourdehif, \\ Paul J. Johnson ${ }^{a}$, David W. Macdonald ${ }^{a}$ and Luke T. B. Hunter ${ }^{g}$ \\ ${ }^{a}$ Wildlife Conservation Research Unit, Department of Zoology, University of Oxford, \\ The Recanati-Kaplan Centre, Tubney, Abingdon, United Kingdom; ${ }^{b}$ Future4Leopards \\ Foundation, Tehran, Iran; ${ }^{\circ}$ Gilan Provincial Office of the Department of the Environment, \\ Rasht, Iran; ${ }^{d}$ Tehran Zoo and Pardisan Rehabilitation Centre, Tehran, Iran; ${ }^{e}$ Wildlife \\ Conservation Society, Bronx, New York, USA; Iran Department of Environment, \\ Pardisan Park, Tehran, Iran; ${ }^{g}$ Panthera, New York, USA
}

\section{(Received 21 November 2017; accepted 20 February 2018) <dummy>}

\begin{abstract}
Intraspecific aggression is one of the most common causes of death in leopards. Here, we report four cases of intraspecific killing amongst Persian Leopards in Iran. A young male leopard was found on 7 June 2008 which, according to camera trap images, had been killed by an adult male over a Red Deer kill, with trauma to his neck in Dorfak No-Hunting Area. A young female that had been fitted with a satellite GPS collar on 6 December 2015 in Tandoureh National Park died on 29 January 2016 at a site where an Urial Sheep ram had been freshly killed. Necropsy results, footprints at the scene of death and camera trap footage all supported the deduction that the animal was killed by a larger female leopard at the kill site. On 13 January 2017, a young, partially eaten female leopard was found with double puncture on the side of her throat. Finally, a rehabilitated adult female fitted with a satellite GPS collar found on 5 December 2017 with a double puncture on her head with several trauma and haemorrhages on her back. These instances seem to be the first documented reports of intraspecific killing among free-ranging leopards in Asia.
\end{abstract}

Keywords: conspecific aggression; intraspecific killing; necropsy; satellite telemetry

\section{Introduction}

Intraspecific hostility is a common feature in large felids which exhibit agonistic behavior toward their conspecifics and occasionally leads to serious injury or death (Macdonald, Loveridge, \& Nowell, 2010). It can occur within or between the sexes and can affect animals of all ages. It is an important source of mortality among the well-studied leopard Panthera pardus populations in South Africa (Balme, Slotow, \& Hunter, 2009) where it has been associated with competition over resources including kills (Steyn \& Funston, 2006) or territory (Balme \& Hunter, 2004). Intra-

\footnotetext{
*Corresponding author. Email: mohammad.farhadinia@zoo.ox.ac.uk 
specific aggression may also involve cannibalism (Steyn \& Funston, 2009) or infanticide (Balme \& Hunter, 2013; Balme et al., 2009).

In Africa, intraspecific strife among adult and sub-adult Leopards is common. It is the predominant documented cause of mortality among female Leopards in protected areas of southern Africa (43\% of causespecific records; Swanepoel et al., 2015). The main causes of aggression between female Leopards appear to be competition for food resources (Balme \& Hunter, 2004) and increased rates of encounter between unfamiliar individuals due to high turnover and thus immigration (Balme et al., 2009). We are not aware of any documented report of these phenomena in Asia and report here the first documented cases of intraspecific killings among Persian Leopards P. p. saxicolor in Iran, observations which are informative for both understanding Leopard behavioural ecology and their conservation. Understanding the primary causes of mortality is needed for the estimation of survival rates and informing management plans of these endangered felids.

\section{Results}

Case 1. To our knowledge, the first documented case of intraspecific killing involving Persian Leopards in Iran occurred in the Dorfak NoHunting Area, located in the Hyrcanian mixed forest in northern foothills of the Alborz Mountains $\left(37.00^{\circ} \mathrm{N} 49.70^{\circ} \mathrm{E}\right.$ to $\left.36.79^{\circ} \mathrm{N} 49.84^{\circ} \mathrm{E}\right)$. The area (c. $379 \mathrm{~km}^{2}$ ) hosts populations of Red Deer Cervus elaphus, Roe Deer Capreolus capreolus, Wild Pig Sus scrofa, Persian Leopard, Grey Wolf Canis lupus and Brown Bear Ursus arctos. On 7 June 2008, forest guards discovered a carcass of a young male leopard with blood and punctured skin on the right dorso-lateral side of the neck (Figure 1, S1). The leopard, which was found near the partially eaten carcass of a Red Deer (Figure S2), was estimated around 2 years old based on tooth wear (Table 1). Tracks of a larger leopard were found around the kill and images taken by a camera trap (DeercamTM, Park Falls, WI) installed after the discovery of the killing revealed an adult male leopard feeding on the Red Deer carcass on the same night (Figure S3).

Case 2. The second case occurred in Tandoureh National Park $\left(355 \mathrm{~km}^{2}\right.$ in size), northeastern $\operatorname{Iran}\left(37.53^{\circ} \mathrm{N} 58.62^{\circ} \mathrm{E}\right.$ to $\left.37.36^{\circ} \mathrm{N} 58.87^{\circ} \mathrm{E}\right)$. The habitat is characterised by steppe mountains with populations of Urial Sheep Ovis orientalis, Bezoar Goat Capra aegagrus, Wild Pig, Grey Wolf and Persian Leopard. A female leopard, estimated from dental examination to be around three years old (Table 1), was fitted with a GPS satellite collar (Lotek Wireless Inc., Ontario, Canada) on 6 December 2015 (see Farhadinia et al., 2017 for details on capturing and 
immobilization procedures). On 29 January 2016 at 10:30, the collar emitted a mortality signal and at 17:00, we found the animal dead ca. 50 metres from a partially eaten adult ( $>5$ year-old) Urial Sheep ram (Figure S4). The ground was covered with snow and tracks revealed the presence of at least two leopards, including a larger specimen. A camera trap (Bushnell, Missouri, USA) installed at the kill site on 30 January photographed an adult female leopard.

An X-ray computed tomography (CT scan) investigation showed that cervical vertebrae C2, C3, C4 and C5 were fractured to various extents (Figure 2). The necropsy revealed extensive subcutaneous and muscular (sterno-hyoid and sterno-mastoideus muscles) haemorrhages on the left lower side of the neck and a comminuted fracture (the bone was crushed into more than three fragments) of the lower left part of the body (cortex and core) of cervical vertebra C3. Protruding sharp-edged splinters, as well as a possible medial non-displaced point fracture of the body cortex of C4 were confirmed. The fracture of C3 was associated with a perforation of the spinal cord canal. The presence of distinct left lateral and ventral perforations of the neck muscles, combined with extensive haemorrhages, suggested a predator bite. The distance between puncture holes was 4.9-5.0 cm, within the variation of rostrum breadth measured on 16 skulls of adult female Persian leopards $(4.3 \mathrm{~cm}$ to $5.5 \mathrm{~cm}$; Farhadinia, Kaboli, Karami, \& Farahmand, 2014). The animal presented a small nongravid uterus without any placental scars of a past pregnancy.

The comminuted nature and location of the fracture, the distance between puncture holes in the neck muscles, the presence of footprints belonging to a second leopard at the site of the kill along with camera trap footages, all suggested that the GPS collared female was killed by another, larger, female leopard. We could not deduce which leopard had killed the Urial Sheep.

Case 3. The third report, again from Dorfak, was a young female found dead on 13 January 2017 (2-3 years old assessed by tooth wear) (Table 1). Necropsy revealed subcutaneous and muscular haemorrhages on the side of the neck associated with two punctures separated by $4.9 \mathrm{~cm}$ (Figure 3), indicative of a leopard bite. In contrast to the two earlier cases, the thoraco-abdominal muscles and ribs on left side had been eaten, but internal organs were intact (Figure S5). The colon was full of spines of Indian Crested Porcupine Hystrix cristata (Figure S6).

Case 4. The last report was an adult female from Roudsar area, located in Hyrcanian mixed forest with similar fauna to Dorfak. Initially found with severe dorso-abdominal musculoskeletal injuries due to an illegal snare on 4 February 2017 near Senjidan village $\left(36.96^{\circ} \mathrm{N} 50.43^{\circ} \mathrm{E}\right)$, the adult 
female underwent orthopaedic lumbar rachis surgery followed by 9 months of soft captive rehabilitation and was released back to her former area on 5 November 2017, fitted with a GPS satellite collar (Vectronic, Germany).

Remains of a young Wild Pig were found in one of the clusters she spent more than one day, and Wild Pig hairs were detected in a fresh scat in another location where the animal spent half day before being found by rangers, suggesting that the animal had fed on this species before death. On 19 December 2017, upon receiving a mortality signal from the collar, she was found dead with leopard hairs in her mouth. She had porcupine spines in her left front limbs and neck (Figure S7), and a deep, haemorrhagic puncture was visible on her head (ca. $6 \mathrm{~cm}$ apart; Figure 4). Post-mortem necropsy indicated that the animal's left zygomatic bone was crushed and the right shoulder muscles were teared apart (Figure S8). The inner side of the right thigh was partially eaten. Several haemorrhages were found on the dorsal part of the body. The deep puncture on the skull and the severely damaged right shoulder and thigh suggested that the female was killed and partially eaten by another leopard.

\section{Discussion}

To the best of our knowledge, these are the first documented reports of intraspecific killing among free-ranging leopards in Asia. Three of the four dead leopards, two females and one male, were young and their body masses (Table 1) were within the reported age/sex-specific weight range (Farhadinia et al., 2014). Competition at a kill was the most likely cause of strife in the first two cases. Steyn and Funston (2009) noted an adult male leopard reportedly killing and consuming three adult female leopards in Botswana's Tuli block. Similarly, a male leopard killed a subadult female in Londolozi Private Game Reserve, South Africa (Hes, 1991). A female leopard was also killed by an adult male leopard on South Africa's Phinda private game reserve in 2012 (A. Braczkowski, pers. comm.).

Determining cause of death in wild animals is often difficult, making even occasional records valuable. Our records are notable in the light of the low density, elusive behaviour and observational difficulties of leopards in west Asia where individual interactions rarely allow scientists to understand the cause of mortality of leopards. Finally, our study highlights the importance of investigating natural causes of mortality, besides anthropogenic casualties which enhance our ability to understand the survival rates and demographic dynamism of leopards, particularly in the conservation-dependent populations of west Asia. 


\section{Acknowledgements}

We thank the Iran Department of Environment for necessary permissions. F. Sasani and M. Mohammadi participated in the necropsy of the second and fourth leopards. H. Fattahian managed the fourth leopard's surgery. S. Abdipour, P. Moghadas, P. Behnoud, S. Firouzi, A. Shahrdari, and A. Daneshvar assisted in field investigations. M. Nosrati, S. Masoudi, M. Marashi, M. Marashi, O. Rahmani, and S. Khosravi collaborated in translocation of the fourth leopard. A. Braczkowski made helpful comments on an earlier draft.

\section{Funding}

The project in Tandoureh was financed by People's Trust for Endangered Species (PTES), Zoologische Gesellschaft für Arten- und Populationsschutz e.V. (ZGAP), Association Francaise Des Parcs Zoologiques (AFDPZ) and a Panthera Kaplan Graduate Award to MSF.

\section{Disclosure Statement}

No potential conflict of interest was reported by the authors.

\section{References}

Balme, G. A., \& Hunter, L. T. B. (2004): Mortality in a protected leopard population, Phinda Private Game Reserve, South Africa: A population decline. Ecological Journal, 6, 1-6.

Balme, G. A., \& Hunter, L. T. B. (2013). Why leopards commit infanticide. Animal Behaviour, 86, 791-799.

Balme, G. A., Slotow, R., \& Hunter, L. T. B. (2009): Impact of conservation interventions on the dynamics and persistence of a persecuted leopard (Panthera pardus) population. Biological Conservation, 142, 2681-2690.

Farhadinia, M., Kaboli, M., Karami, M., \& Farahmand, H. (2014): Patterns of sexual dimorphism in the Persian Leopard (Panthera pardus saxicolor) and implications for sex differentiation. Zoology in the Middle East, 60, 195-207.

Farhadinia, M., Memarian, I., Hobeali, K., Shahrdari, A., Ekrami, B., Kaandorp, J., ... Macdonald, D. W. (2017): GPS collars reveal transboundary movements by Persian leopards in Iran. Cat News, 65, 28-30.

Hes, L. (1991): The leopards of Londolozi. Struik Winchester, Cape Town. South Africa.

Macdonald, D. W., Loveridge, A. J., \& Nowell, K. (2010): Dramatis personae: an introduction to the wild felids. Pp. 3-58. In D. W. Macdonald \& A. J. Loveridge (Eds), Biology and Conservation of Wild Felids. Oxford: Oxford University Press.

Steyn, V., \& Funston, P. J. (2006): A case of cannibalism in leopards. South African Journal of Wildlife Research, 36, 189-190.

Steyn, V., \& Funston, P. J. (2009): Land-use and socio-spatial organization of female leopards in a semi-arid wooded savanna, Botswana. South African Journal of Wildlife Research, 39, 126132.

Swanepoel, L. H., Somers, M. J., van Hoven, W., Schiess-Meier, M., Owen, C., Snyman, A., ... Boshoff, W. (2015): Survival rates and causes of mortality of leopards Panthera pardus in southern Africa. Oryx, 49, 595-603. 
Table 1. Morphological measurements of four Persian Leopards (Panthera pardus saxicolor), killed by other leopards in northern Iran.

\begin{tabular}{lcccc}
\hline Parameters & Dorfak & Tandoureh & Dorfak & Roudsar \\
\hline Date & 7.06 .2008 & 29.01 .2016 & 13.01 .2017 & 19.12 .2017 \\
Age (years) & 2 & 3 & $2-3$ & $>5$ \\
Sex & 0 & + & $q$ & + \\
Body mass (kg) & 41 & 38 & 40 & NA \\
Head and body length $(\mathrm{cm})$ & 102 & 126 & 110 & NA \\
Tail length (cm) & 82 & 90 & 74 & NA \\
Shoulder height $(\mathrm{cm})$ & 68 & 68 & NA & NA \\
\hline
\end{tabular}

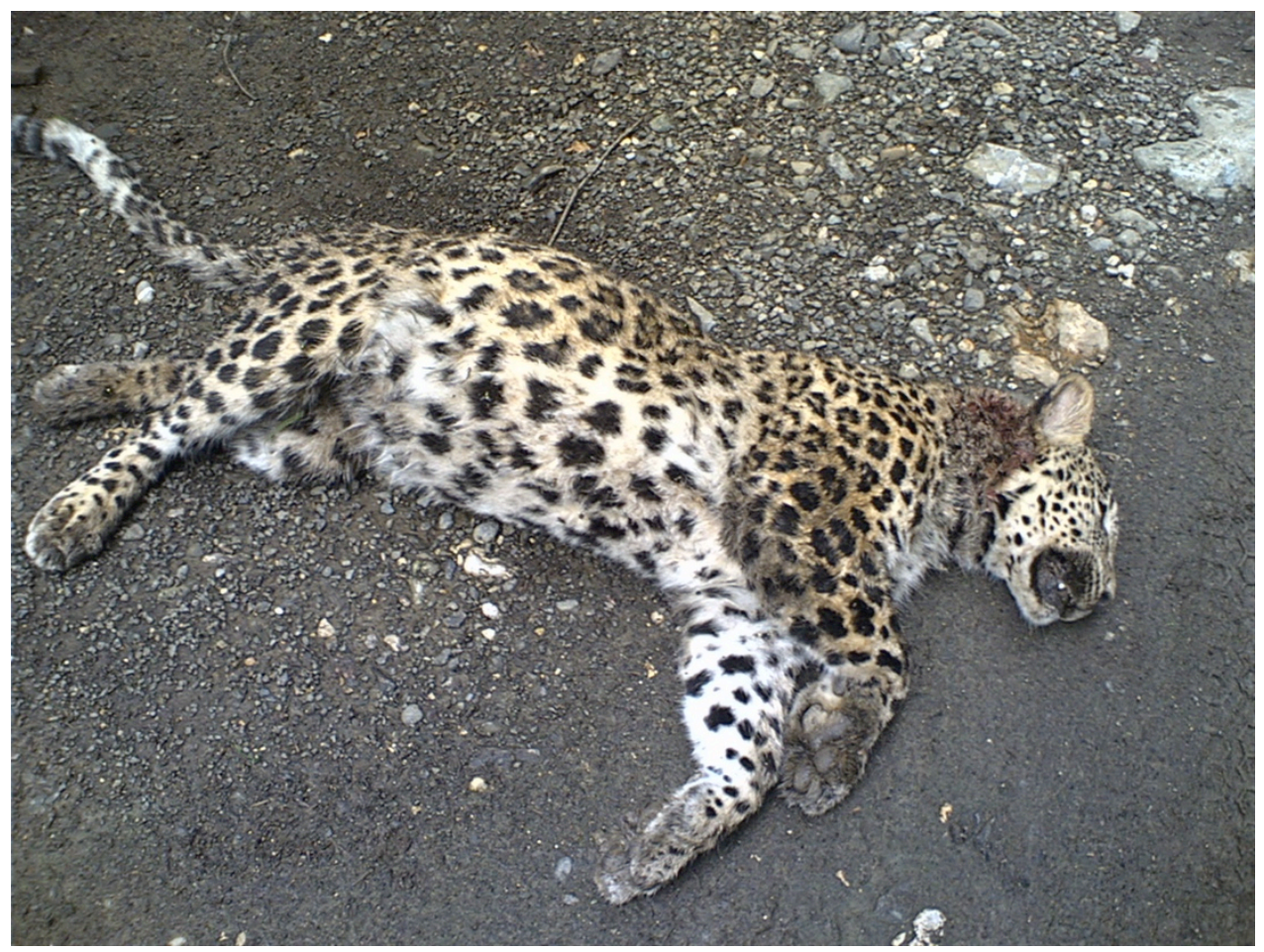

Figure 1. A young male leopard killed by a larger conspecific in Dorfak No-Hunting Area, June 2007 (Photo: H. Alinezhad). 


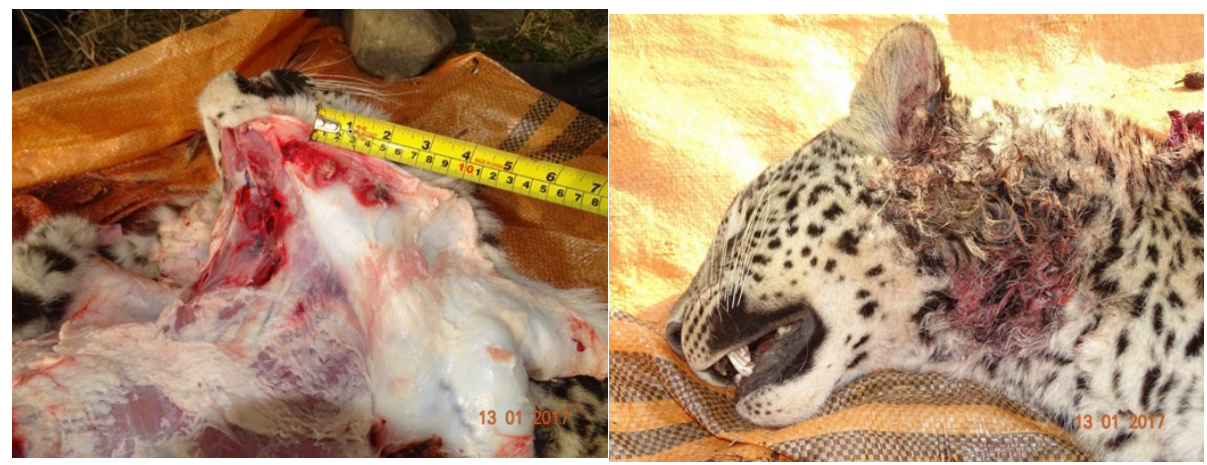

Figure 2. Position of punctures and the distance between puncture holes on the left side of the neck in a young female Persian Leopard, Dorfak No-Hunting Area, January 2017 (Photo: E. Hadipour).

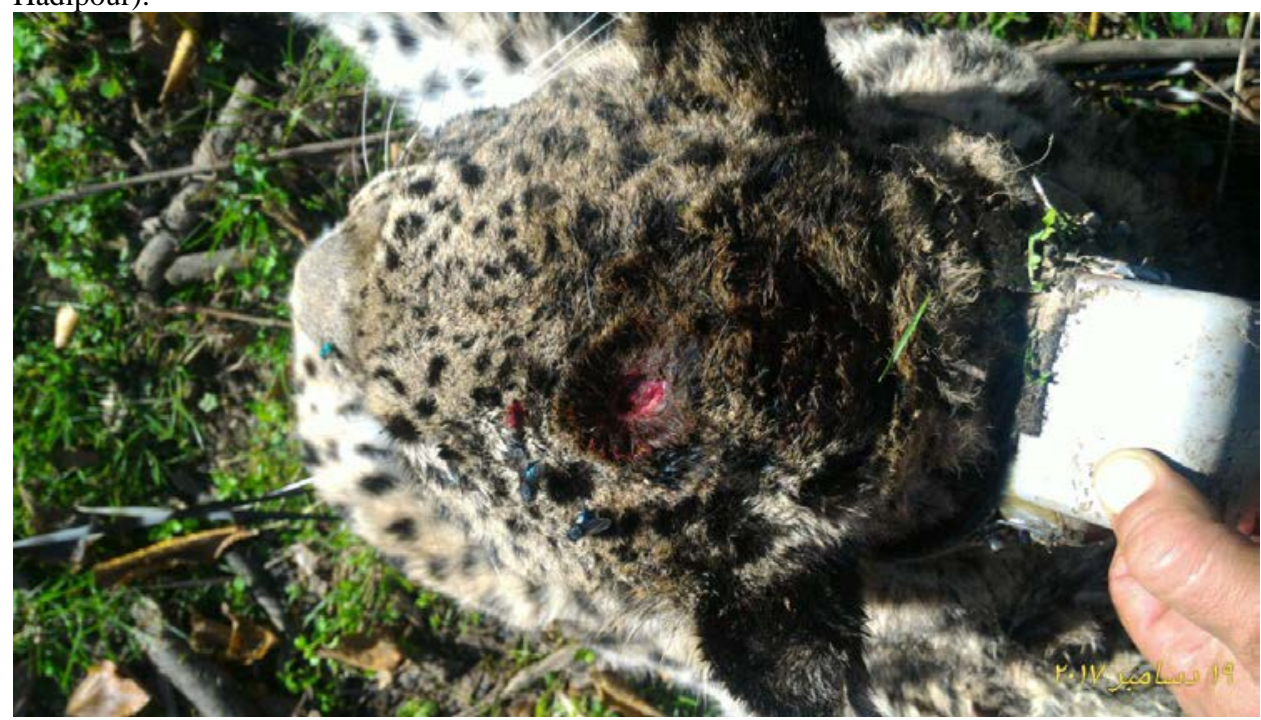

Figure 4. Punctures on the head of an adult female leopard in Roudsar Area, December 2017 (Photo: S. Abdipour).

Please send us your figures in .tif or .jpg format 